\title{
LINKING CHILD HEALTH, MATERNAL LABOUR FORCE PARTICIPATION AND HOUSEHOLD ASSET ENDOWMENTS IN CAMEROON: WHAT THE PEOPLE SAY
}

\author{
Mbu Daniel Tambi, Lecturer \\ Department of Agricultural Economics, University of Dschang, Cameroon \\ E-mail: tambimbu@yahoo.com
}

Aloysius Mom Njong, Associate professor

Department of Economics, University of Bamenda, Cameroon

E-mail: mom aloys@yahoo.fr

Menjo Francis Baye, Professor

Department of Economics and Management, University of Yaounde II, Cameroon

E-mail: bayemenjo@yahoo.com

\begin{abstract}
This paper is targeted objectives: to document the determinants of child health as informed by focus group discussion, to analyze what the people say concerning the relationship between child health and maternal labour force participation, to explore the perception of the people on the effects of child health on asset accumulation and to suggest public policies on the basis of the findings. We used seven focus groups to explore what the people say based on different health domains: access to public goods; inputs to health; benefits from better health; better child health and complementary activities; benefits of maternity leave and better child health, decision making concerning family health. Each focus group was made of eight participants: housewife, traders, farmers, drivers, teachers, technicians, medical personnel and military drawn from different religious groups: catholic, protestant mainline, protestant non-mainline, other protestant, Muslim, systemic and traditional belief. We observed that, parents make used of the extra time accrue to them due to better health for their children and family to do extra work that fetched them money. The increased family income is use to send their children to better schools, carter for their wellbeing as well as to promote asset growth and redistribution, thus, improving economic well-being and reducing poverty. In case of retirement or sudden retrenchment from the labour market, parents make use of the accumulated assets to increase their family income and maintain well-being, hence, reducing the psychological trauma on parents due to poverty. Based on these findings, we recommend that decision makers and actors concern with child health issues should considered, ease and promote child health outcomes. This is a key to narrowing the poverty and inequality gap between the poor and non-poor, rural and urban household residence, married and unmarried, employed and the unemployed, promote maternal labour force participation and household wealth accumulation in Cameroon.
\end{abstract}

\section{KEY WORDS}

Cameroon; Child health; Household asset endowment; Maternal labour force; Participation.

The use of focus group discussion in health issues is gradually gaining grounds in health economics. Focus Group Discussion (FGD) entails gathering people from similar backgrounds or experiences together to discuss a specific topic of interest (Bender and Ewbank, 1994). It may also be considered as a group discussion of approximately 6 to 12 persons who are guided by a facilitator, during which group members talk freely and spontaneously about issues of interest such as child health. The strength of focus group relies on allowing the participants to agree or disagree with each other so that it provides an insight into how people think about health issues. The range of opinions, ideas, inconsistencies and variations that exist in the discussion in terms of beliefs, experiences and practices provide adequate information for qualitative research analysis (Merton, 1956; Zimmerman et al., 1990). 
Focus groups can reveal a wealth of detailed information and deep insight about the relationship between child health, maternal labour and household asset. When well executed, a focus group creates an accepting environment that puts participants at ease, allowing them to thoughtfully answer questions in their own words and add meaning to their answers on child health. Surveys are good for collecting information about people's attributes and attitudes, but if one needs to understand things at a deeper level then focus group discussions is better.

Child health influences on labour market and economic outcomes/asset endowments have been a major inquiry in development studies since the last decades. Focus group discussions attempt to explore a specific set of issues such as people's views and experiences on child health and child health related effects (Crokett et al., 1990), mental illness (Grunig, 1990), contraception use (Zimmerman et al., 1990; Barker and Rich, 1992) or drunk-driving (Basch et al., 1989). The group is focused as it involves some kind of collective activity such as examining child health or simply debating on a particular set of health questions. Focus groups are distinguished from the broader category of group interviews by the explicit used of the group interaction as research data (Merton, 1956; Morgan, 1988) and are a strong instrument in analyzing health issues. Focus group discussion was first mentioned as a market research technique in the 1920s (Bogardus, 1926; Basch, 1987) and was used by Merton in the 1950s to examine people's reactions to wartime propaganda (Merton, 1956).

As noted by Grossman (1972), health is a crucial contributor to a person's stock of human capital, the changing bundle of individual skills, knowledge and capabilities that everyone possesses (other contributors to human capital are; work experience, training and motivation). Human capital is a key determinant of maternal labour market outcomes and wealth accumulation as it is expected to be positively associated with maternal productivity and the schooling of children. Hence, the recognition of the central role of human capital in labour market outcomes and HAE has made it the focus of government policies which aim to lift MLFP and increase asset endowments. The rationale behind this type of policy is that, by endowing children and mothers with more human capital, through better medical care; illness prevention, detection and treatment and more education and training, both labour demand and labour supply will be stimulated.

As a component of human capital, child health is a key factor in the creation of wealth (Lucas, 1993; Mwabu, 1998). Although the relationship between health and wealth realized in terms of productivity appears to be simple and straight forward at the surface, the underlying process and intricacies behind this relationship are quite complicated and complex in nature, both conceptually and methodologically. Being an intrinsic factor, it is difficult to conceptualize health status and its relationship on individual behaviour. There is a strong, positive correlation between wealth and health. It is possible that broadly defined health expenditures, such as smoking decisions, exercise; diet and preventative medical care (such as consumption of cholesterol drugs) indeed affect health (De Nardi et al., 2010).

The link between health and labour force participation is such that; firstly poor child health may lead to a reduced likelihood of labour force participation for several reasons: Child disability can cause absenteeism and impair motivation and performance at work (Waghorn and Lloyd, 2005). Prolonged absenteeism might eventually lead to complete withdrawal from the labour market. Mothers with depression due to child ill health might also face limited employment opportunities if an episode of impaired motivation is interpreted by employers as reflecting a low overall motivation level (Waghorn and Lloyd, 2005) or if employers ascribe low motivation to everyone who suffers from depression. Mothers with anxiety disorders also face employment restrictions. Thus, using 1998 Australian data, Waghorn and Lloyd (2005) found that the most commonly cited employment restrictions for people with anxiety disorders are, in order of importance: restrictions on the type of job performed; the need for a support person; difficulty in changing jobs and a limitation on the number of hours worked.

Based on cross-country data, it was also mentioned that better health status from an individual point of view means better utilization of labour power, which implies enhanced productivity (Kumar and Mitra, 2009). Health is found to have a causal effect on economic 
prosperity of males during middle and older ages. Using body mass index of a mother as an endogeneous variable, evidence in favour of a positive and significant ill health and productivity nexus has been strengthened. It is argued that if a worker is healthier, less susceptible to disease, and more alert and more energetic, then he or she will be more productive and command higher earnings that enhance household asset endowments (Thomas and Elizabeth, 2002; Soares, 2007).

Many authors over the years have attempted to link child health to other variables (such as; labour, wealth/income, education, migration, poverty, economic growth) using either household panel or cross section data and they offer valuable insights (for instance Grossman, 1972; Case and Deaton, 2005; Glewwe, 2008; De Nardi et al, 2010; Baye, 2010; Tambi and Nkwelle, 2013). Unfortunately only few authors in Europe and America have used FGD to linked health to other variables (Merton, 1956; Zimmerman et al., 1990; Crokett et al., 1990; Barker and Rich, 1992; Bender and Ewbank, 1994). However, we know not of any published study in SSA especially in Cameroon that have attempted to link child health to either MLFP or HAE using FGD. This paper is therefore new in the Cameroon context as we attempt to evaluate what the people say concerning the association of child health, maternal labour force participation and household asset endowments from FGDs. To do this, we consider the following objectives: to document the determinants of child health as informed by focus groups discussions; to analyze what the people say concerning the association between child health and maternal labour force participation; to explore the perception of people on the effects of child health on asset endowment; to suggest public policies on the basis of our findings.

\section{LITERATURE REVIEW AND THEORETICAL FRAMEWORK}

Literature Review. It has been outlined in the literature that over the life cycle, female labour force behaviour is governed by various factors and very complex mechanisms that determine the decision to enter, stay on, or leave the labour market (Lelièvre-Gauthier, 1994). These factors include: household characteristics (presence, number of children and health of the children, structure of household and domestic workload); economic (that is the labour market structure) and individual (skills, marital status, labour force attachment, incentives and career expectations) (Tsafack and Zamo-Akono, 2009).

Bender and Enbank (1994) in their study of children and young people's well-being noted that focus group discussions confirmed that a self-report measure focusing on the immediate lives of children and young people would linked well with their interests and concerns. Spontaneous responses to open questions suggested that eight of their initial set of nine domains were relevant; getting the information you need/information provision was relatively unimportant to those taking part. The discussions suggested that children's understanding of questions based on their domains were improved by specifying who might be the source of help or support and by concrete and specific statements. Still in their study, the focus groups highlighted areas of overlap between the domains and suggested ways in which they could be made more discrete, where some aspects would make more sense if moved to other domains and how some domain specification could be improved and refined. Their views about what was important to their quality of life also raised issues around the scope and coverage of the domains. Some extra domains were identified but were not suitable for taking forward in their measure since they were ot directly linked to children's services.

Thus, Kitzinger (1994) in support of FGD suggested ten main advantages to be gained from the interaction between participants, such interaction include: (1) highlights the respondents' attitudes, priorities, language and framework of understanding; (2) encourages a great variety of communication from participants - tapping into a wide range and form of understanding, (3) helps to identify group norms; (4) provides insights into the operation of group/social processes in the articulation of knowledge (e.g. through the examination of what information is censured or muted within the group); (5) encourage open conversation about embarrassing subjects and facilitate the expression that might be left underdeveloped in an interview. Through detailed attention to the interaction between different members of the group a researcher can: (6) explore difference between group participants and work with 
them, given that, participants reflect upon each other's ideas, ensure that the data is organic or interconnected; (7) use the conflict between participants in order to clarify why people believe what they do. (8) Examine the questions that people ask one another in order to reveal their underlying assumptions and theoretical frameworks; (9) explore the arguments people use against each other, identify the factors which influence individuals to change their minds and document how facts and stories operate in practice-what ideological work they do; (10) analyses how particular forms of speech facilitate or inhibit peer communication, clarify or confuse the issue (in ways directly relevant to improving communication).

Following Kitzinger (1994) this paper is not arguing that the group data is either more or less 'authentic' than data collected by interviews; instead it is based on the 'premise' that 'all talk through which people generate meaning is contextual and that the contexts will inevitably somewhat colour the meaning (Dahlgren, 1988). It is a predictable sign of the dominance of the interview paradigm that when researchers have found differences between data collected by interviews and group discussion they have sometimes blithely dismissed the latter as 'inaccurate'. Hoijer for example, is one of the few authors that have critically addressed both interviews and group discussions. She used both techniques in her study of audience understandings of television programmes. However, at one point she states that comparing interpretations and opinions expressed individually with what is later said in a group discussion, there are always several cases of diversion (Hoijer, 1990).

In this perspective, Tambi and Nkwelle (2013) used a cross section data to examine the socioeconomic effects of child health on maternal labour supply in rural Cameroon with an application of the chi square they observed a strong correlation between child health and maternal labour force participation. This imply that improved child health reduces medical expenditure on the child in times of illness, the psychological trauma of staying at home to take care of the child is also reduced, giving the mother the extra time to participate in the labour market. The time spent by women in activities such as food preparation, breastfeeding, collecting water and fuel and seeking preventative and curative medical care is an important input into the production of infant or child health. The extra time at the disposal of mothers can be plough into productive activities that can procure extra income for the purchase of household asset (Angrist and Evans, 1998).

Theoretical Framework. Critically, in this framework we used the complementary interaction theory as proposed by Glaszer and Strauss (1967) and adopted by Kitzinger (1994). Group work ensures that priority is given to the respondents' hierarchy of importance, their language and concepts, the framework for understanding the world. In fact, listening to discussions between participants gives the researcher time to acclimatize to, for example their preferred words of speaking about child health and health related issues clarify the researcher on areas of doubt. In exchange between participants in a group, people's different assumptions are thrown into relief by the way in which they challenge one another, the questions they ask, the evidence people bring to bear on an issue, the sources of their information will all be an enlightenment on many important issues to be discussed.

Glaszer and Strauss (1967) noted that arguments seem to sway the opinion of members in a group discussion. When analyzing the script of a group discussion it is well worth having special coding categories for certain types of interaction between participants such as question, cited sources, deferring to the opinion of others and changes of mind; when one participant describes an occasion, when they think they might have out themselves at risk - what queries are raised by the co-participants or now do they seek to reassure their friends? When an argument breaks out, what sort of evidence seems to 'work' in influencing the opinion of others? And what is going on when people appear to change their minds in response to information or theories presented by co-participants.

In addition to this theoretical framework and bearing in mind that our focus is to verify the link between child health; maternal labour force participation and asset endowments evidence from FGD, there are many other ways to examine these links. This analysis can start from ideas dating back at least to Grossman (1972), who argued that health is the cumulative result of investment and choices (along with randomness) that begin in the utero. He models household utility as being a function of consumption and health, where individuals 
make optimizing decisions over the production of health along with consumption. Surprisingly, given the obvious centrality of health to economic decision-making and wellbeing, numerical models of lifecycle consumption choices generally treat health in a highly stylized fashion. The most common approach in the literature (Hubbard et al., 1995) ignores health as an argument of utility. Instead, lifetime budgets are subject to medical expense shocks that proxy for health shocks. Households respond to exogenous medical expense shocks by decreasing consumption and by saving for precautionary reasons.

\section{METHODOLOGICAL SETTING}

The main method applied in this paper is to link child health, MLFP and HAE is that of focus group discussion. Focus groups are often used to explore subjective meaning and understanding and are particularly useful to identify relevant domains when developing questionnaires (Morgan, 1997). Focus groups have been used successfully to explore the perspective of children and young people in health, education and psychology research (Porcellato et al., 2002; Ellermann, 2007). There is also a growing body of work that has used focus groups to understand how children and young people perceive quality of life and on the value of immunization or traditional practices preferred by an ethnic subgroup concerning pregnancy and childbirth (Ronen et al., 2001; Detmar et al., 2006; Beresford et al., 2007; Chavez et al., 2007). Assessing levels of health on various domains is a key component of measuring family health, evaluating the impact of child health interventions and monitoring health levels. Meaningful comparisons across groups are useful in setting goals for the improvement of child health and charting progress towards attaining these goals. Comparisons are also useful within group in order to understand differences in health levels across children and to measure health inequalities.

In this study, a total of seven focus group discussions are carried out with men and women of childbearing age (20-50 years old) in different occupations, to assess their perceptions and knowledge of child health and nutrition in relation to MLFP and HAE in Cameroon. The different groups are selected based on their religious affiliations.

Research Instruments to gauge Child health effects on MLFP and HAE. Focus groups are a powerful instrument often used to understand children's health effects on other variables in this study, we explored what the people say on the effects of child health on MLFP and HAE with the use of FGD as our instrument of measurement (Ronen et al., 2001). FGD has been used as a powerful health instrument in many contemporary studies (for example, Grewal et al., 2006; Wee et al., 2006). Focus groups was also used to ask parents about what constitutes their children well-being in an Australian study interested in developing child-centered indicators (Fattore et al., 2009) and more specifically with disabled children and young people in relation to outcomes from support services (Beresford et al., 2007).

Children's effects are increasable being sought and reported to feed into policy and practice development. For example, Counterpoint qualitative research sought to identify factors comprising a good content in childhood. They found that children and young people identified a similar range of issues as parents but used different language. The children and young people identified playing (having fun), getting prizes, stars and praise, feeling protected, cared for and/or loved being understood listened to/able to talk to parents, getting the things you want, sports/activities (Counterpoint, 2008).

Reliability and Validity of focus group Data. Focus group data can be tested for reliability by comparing the responses of focus groups, for instance, if most groups mention vaccination as a major health input, then one can be confident of the reliability of reporting. However, if no two groups give the same response as an explanation of vaccination, then one cannot place too much faith in the reliability of the responses. Secondly, one can also compare focus group findings with those from other methods of data collection such as DHS. The narrative statements in Table 1 demonstrate another example of reliability testing across groups. Each of the seven groups gave similar answers with respect to health input, benefit and complementary activities, even though each group's answers were expressed in different ways. 
In order to avoid jeopardizing the validity of focus group data, every precaution must be taken to avoid finishing participant's responses or asking leading questions that can hinder validity, since the purpose of a focus group is to gather data relevant to the respondents' point of view not to provide them with 'correct' textbook responses. This of course does not preclude the appropriateness of giving information in response to questions raised by those being interviewed. Ideally, such a question-and-answer session should be separated from data collection by a clear break in the proceedings.

\section{DATA SOURCE AND SAMPLE CHARACTERISTICS}

Focus group aims, access and sampling. As seen above, the principal aim of this paper is to examine what the people say on child health effects on maternal labour force participation and household asset endowments. In this section, the principal role of the focus group is to examine in real terms how better child health can directly or indirectly affect MLFP and HAE. We derived seven focus groups: (1) Roman catholic; (2) Protestant Mainline (Presbyterian, Baptist, Methodist...); (3) Protestant non-mainline (Pentecostal, Evangelical, Church of Christ...); (4) Others protestant (Jehovah witness, Seventh Day Adventist); (5) Muslim (Sunni or Shia); (6) Systemic group (Bahai, Hindu, Atheist, Animist) and (7) Traditional believe (Pagans, no religion). In a complete focus group, we select eight participants in the interested religious group. To ensure robustness in our results, we make use of professions such as: teachers, medics, traders, farmers, drivers, housewives, military and technicians which are very committed jobs. To ease organization, logistics and the flow of discussions, the group meeting of the discussants is the religious group place of worship.

There are many reasons why we chose to work with pre-existing groups - clusters of people who already knew each other through living, working or socializing together. We did this in order to explore how people might talk about child health within the various and overlapping groupings within which they actually operate. Religious/faith mates, prayer partners, flat mates, colleagues, family and friends - these are precisely the people with whom one might 'naturally' discuss such topics as child health (Middleton and Edwards, 1990). Although the practice of using existing friendship groups is discouraged by standard market research texts such fear seemed unjustified in our case. By using pre-existing groups we shall be able to tap into fragments of interactions which is approximated to "naturally occurring' data. The fact that research participants already knew each other had the additional advantage that friends and colleagues could relate each other's comments to actual incidents in their shared daily lives. They often challenged each other on contradictions between what they are professing to believe and how they actually behaved.

Above all it is useful to work with pre-existing groups because they provide one of the social contexts within which ideas are formed and decisions made. Khan and Manderson (1992) recommended the explicit use of informal as well as formal 'focus groups' for anthropological research into understandings of health and illness in village settings. They worked with groups composed, for example, of a woman, her daughter, daughter-in-law and unrelated immediate neighbours. Such natural clustering of people' they pointed out, 'represent in a loose fashion the resources upon which any member of the group might draw information and advice. This is a group that may weave or repair nets together while watching over their children and discussing the events of the previous day. It is precisely this natural social network which provides the scripting for the management of an illness eventwhat to do with a child with bloody diarrhea, for example how to nurse high fever or who to call in the case of threatened miscarriage (Khan and Manderson, 1992). Also it's worth mentioning that the choice of our sample occupation such as driving, housewife, trading, teaching, technicians, farming, military and medics is very important because these are jobs that highly compete with time as far as child health is concern.

Focus group design, operation and analysis. The basic topics and domains discussed in the focus group are indicated below. An initial definition for each topic is developed to facilitate the discussions and to identify initial areas of overlap or content that might warrant separation into new topics. This is listed in table 1 with some information about the use of the domain in the outcome assessment scales. 
Table 1 - Domains developed for focus groups

\begin{tabular}{|l|l|}
\hline \multicolumn{1}{|c|}{ Topic of Discussion } & \multicolumn{1}{c|}{ Domain } \\
\hline $\begin{array}{l}\text { Access to Public } \\
\text { Goods }\end{array}$ & $\begin{array}{l}\text { Here we are interested to know if the participants have access to public goods such as } \\
\text { health facilities (formal, informal); schools for children; public transport; adult literacy } \\
\text { programs; proximity to tarred roads; nearness of markets. }\end{array}$ \\
\hline Inputs to Health & $\begin{array}{l}\text { Our objective is to determine the health interventions that improve mother and child } \\
\text { health, such as: vaccinations - concerns about child mortality, - sanitation facilities (this } \\
\text { include type of toilette, source of water). }\end{array}$ \\
\hline $\begin{array}{l}\text { Benefits from Better } \\
\text { Health }\end{array}$ & $\begin{array}{l}\text { We wish to know how better mother and child health will benefit the family now and in } \\
\text { the future in terms of: family income; extra time for additional work; labour market } \\
\text { participation opportunities; self employment opportunities; quality of schooling; child } \\
\text { future job and income earning opportunities. }\end{array}$ \\
\hline $\begin{array}{l}\text { Better child Health } \\
\text { and Complementary } \\
\text { Activities }\end{array}$ & $\begin{array}{l}\text { The objective here is to know if better child health encourages household heads to do } \\
\text { complementary (additional) activities that can improve family income. The question to } \\
\text { ask is to: (1) identify the complementary or additional activities that could increase } \\
\text { production and incomes if the children are enjoying good health. Also if a parent were to } \\
\text { have extra time because the children are in good health, what can one do to improve } \\
\text { family income or family status? }\end{array}$ \\
\hline $\begin{array}{l}\text { Benefits of Maternity } \\
\text { Heave and Better child }\end{array}$ & $\begin{array}{l}\text { Here we suppose that mother is working and entitled to maternity leave, what will the } \\
\text { effect of better child health be in terms of secondary income earning or adult schooling } \\
\text { opportunities? }\end{array}$ \\
\hline $\begin{array}{l}\text { Decision Making } \\
\text { concerning Family } \\
\text { Health }\end{array}$ & $\begin{array}{l}\text { We are interested to know, who actually takes decisions concerning family health: } \\
\text { mother, father or both. }\end{array}$ \\
\hline Health Interventions & $\begin{array}{l}\text { Now let suppose the mother/father and children are in good health how can government, } \\
\text { NGOs, churches, the community and/or private sector be expected to help parents } \\
\text { exploit the extra time at the disposal of their families? (For instance, credit opportunities, } \\
\text { other special programs). }\end{array}$ \\
\hline
\end{tabular}

Source: author (designed for FGD)

To realize our objective, we make use of the spiritual authority (pastor, priest, imam, and leader) to establish the focus group in their respective religious group. Each session of focus group if the group members accepts and will last discussion is audio/video recorded and lasted for 2 hours. At each group meeting, soft drinks are distributed to the participants. At the start of the group meeting, the project and the aims of the discussion were outlined. Confidentiality and anonymity was explained and the ground rules of group discussions outlined and consent forms collected.

The groups start with the participants, including the moderator (researcher) taking in turns to introduce themselves and tell the group the best thing they had done during the rainy season and what they are looking forward to do in the next season or so. A structured topic guide is used by the moderator. This guide includes open questions similar to those used by Young et al (2007) and Beresford et al (2009). Open questions are asked first and so on (see also Wee et al., 2006). To encourage and maximize participation participants is asked to provide more detail information, to elaborate further or to comment on something another participant had said. Table 2 shows the place and language used in the respective focus group meeting as well as the number and percentage of female and male participants in the focus group.

Table 2 - Place, Language and number of Focus Group Participants

\begin{tabular}{|l|c|c|c|c|c|c|}
\hline \multicolumn{1}{|c|}{ Focus Group } & Locality/Region & Language & Female & Male & Female (\%) & Male (\%) \\
\hline Roman Catholic & Bafia - Centre & French & 5 & 3 & 62.5 & 37.5 \\
\hline Protestant Mainline & Socapalme - South & French / English & 4 & 4 & 50 & 50 \\
\hline Protestant non-mainline & Andom - East & French & 4 & 4 & 50 & 50 \\
\hline Other Protestant & Melong - Litoral & English / French & 6 & 2 & 75 & 25 \\
\hline Muslim & Dschang - West & French / English & 0 & 8 & 0 & 100 \\
\hline Systemic group & Mamfe - South West & English & 5 & 3 & 62.5 & 37.5 \\
\hline Traditional believers & Batibo-North West & English & 5 & 3 & 62.5 & 37.5 \\
\hline \multicolumn{1}{|c|}{ Total } & 7 regions & 2 & 29 & 27 & 51.78 & 48.22 \\
\hline
\end{tabular}

Source: author (designed for FGD) 


\section{FINDINGS FROM THE FOCUS GROUPS AND PROPOSED SET OF OUTCOME DOMAINS}

In this section, we present the findings of the different domains of what the people say in focus group discussions before finally presenting the main results of the FGDs in linking child health, MLFP and HAE in Cameroon. The participant's spontaneous responses to the open questions suggested that the seven proposed domains are relevant and important. Spontaneous remarks are made by the participants that corresponded to some degree to our domains of health inputs such as enema, education and counseling, direct clinical care and divine prayers.

Views about the Access to Public Goods. Table 3 summarizes what the people say about the access to public goods.

Table 3 - Summary of what the people say about the access to public goods

\begin{tabular}{|c|c|c|c|c|c|c|c|c|}
\hline Public Good & RCg & PML & PNML & OP & Mg & Sg & Tg & Groups Mention item (\%) \\
\hline Medical Centres & 1 & 1 & 2 & 2 & 1 & 2 & 2 & 100 \\
\hline Schools & 1 & 1 & 1 & 1 & 1 & 1 & 1 & 100 \\
\hline Road & 1 & 1 & 1 & 1 & 1 & 2 & 2 & 100 \\
\hline Adult litracy Program & 0 & 0 & 0 & 0 & 0 & 1 & 0 & 14.28 \\
\hline Market & 1 & 1 & 1 & 1 & 1 & 1 & 1 & 100 \\
\hline N & 8 & 8 & 8 & 8 & 8 & 8 & 8 & - \\
\hline
\end{tabular}

Source: author from FGD

NB-1: $R C g$ = Roman Catholic group, $P M L=$ Protestant mainline, $P N M L=$ Protestant non-mainline, OP= Other Protestant, $\mathrm{Mg}=$ Muslim groug, $\mathrm{Sg}=$ Systemic group, $\mathrm{Tg}=$ Traditional group, $\mathrm{N}=$ Number of participants.

NB-2: $0=$ if public good is absent; 1 = if public good is available but difficult accessibility, $2=$ if good is available and very accessible.

From Table 3 we observed that all focus groups acknowledge the availability of medical centers in their locality however, about 42.85 percent of the participants revealed that medical centers are difficult to access. In the same line, they all said schools are available and accessible, while 71.42 percent noted that the roads are not accessible. Adult literacy program is available as underscore by 14.42 percent of the participants. A 100 percent of the participants confirm the existence and easy accessibility of markets.

Generally, from what the people say, we observed that most participants preferred to talk about their place of origin as to their present resident. They claimed that people except otherwise love and cherish their place of origin. Participants noted that government primary schools are available but trained teachers are lacking. In most communities the participants noted that, at times the chiefs will asked the brilliant sons and daughters that have completed the secondary level to spend at least one year in the community school to teach the younger ones before proceeding for higher education. This point is strongly supported by participants from South West region, North West region and the East regions. The secondary schools are available but their distant are usually very discouraging for the young scholars.

From the information gathered in our different religious groups, adult literacy programs are generally absent as noted by almost all participants, roads are available though not tarred, in the dry season they are quite accessible, however there are no permanent public transport vehicles. Cars occasionally run the roads even the local transport cars (clando) at times are not reliable. However, the presence of motor taxies is a good substitute despite the numerous accidents they are prone to, noted some of the participants.

About 57.14 percent of participants from the different groups mentioned that markets are available but in most of them only perishable items are sold. Exceptionally on real market days especially in the month of December where there are a mixture of tangible, intangible and perishable items are sold. The business people are often discouraged to take their goods to villages and local communities since the people are often skeptical of higher prices.

Hospitals are usually distant noted some participants; which has motivated many people to resolved to visiting traditional practitioners for their health issues except on some 
serious cases. The people said the drugs are expensive, the doctors hardly available in public medical centers especially during the period of political campaigns. Other participants acknowledge the presence of hospitals in their locality but strongly emphasize that those hospitals are not reliable as consultation and drugs are expensive. Some participants even said they prefer to take treatment at home than to be hospitalized in the public hospitals, except in critical conditions.

Views about the Inputs to Health. What the people say in relation to inputs to health is summarize in Table 4.

Table 4 - Health Input as mentioned by focus group

\begin{tabular}{|l|c|c|c|c|c|c|c|c|}
\hline \multicolumn{1}{|c|}{ Health Input } & RCg & PML & PNML & OP & Mg & Sg & Tg & Groups Mention item (\%) \\
\hline Vaccination & 1 & 1 & 1 & 1 & 1 & 1 & 1 & 100 \\
\hline Sanitation & 1 & 1 & 1 & 1 & 1 & 1 & 1 & 100 \\
\hline Nutrition & 1 & 1 & 1 & 1 & 0 & 0 & 1 & 71.42 \\
\hline Education and Counseling & 0 & 1 & 1 & 0 & 0 & 0 & 0 & 28.57 \\
\hline Direct clinical care & 1 & 0 & 1 & 0 & 1 & 0 & 0 & 42.85 \\
\hline Enemma/herbs & 1 & 1 & 0 & 0 & 0 & 0 & 1 & 42.85 \\
\hline Divine prayers & 1 & 1 & 1 & 1 & 1 & 1 & 0 & 85.71 \\
\hline
\end{tabular}

Source: auther from FGD

NB-1: $R C g=$ Roman Catholic group, $P M L=$ Protestant mainline, $P N M L=$ Protestant non-mainline, $O P=O t h e r$ Protestant, $\mathrm{Mg}=$ Muslim group, $\mathrm{S} g=$ Systemic group, $\mathrm{Tg}=$ Traditional group, $\mathrm{N}=$ Number of participants. NB-2: $0=$ if not mention by group; 1 = if mention by group

Almost all participants in the different focus groups mentioned that for the family to be in good health, especially the child, there is a serious need to watch over the sanitation conditions of the child. Most groups emphasize with classical examples, the role of clean water in one's life, they pointed out illnesses such as: typhoid, dysentery, Cholera, vomiting and diarrhea that are caused by dirty portable water, while standing water provokes malaria, skin diseases, chicken pox, and measles. An argument broke out in the Roman Catholic group when a man said "parent can only control their children at home but not everywhere they go such as school", implying that it's God that is protecting children, parent only have to pray. Others noted 'faith without action is useless', another said 'thou shall not tempt the Lord thy God', Though it was a heated debate, however they concluded that while praying, parent should do their best to take care of their children especially what they drink, their play ground and where they empty their bowels.

Another heated debate arose on food consumption. Some parent participants especially in the systemic group emphasize that 'whatever the child wants to eat should be of quality because children that eat well grow well. They attempted to compare the children born in a typical remote village where baby's milk is absent (phosphatine, cerelac, milk) and other children's beverages to those born in the city with all types of refined children's food. The argument was strongly supported by other groups, however; some few participants refused the perception by noting that children born in cities are relatively weaker, vulnerable and slow to action as compared to those born in rural communities without quality children's food. We notice that parent teachers, nurses and traders had a contrary view in which they reminded group members not to neglect the high quality natural food that the rural children are consuming. They generally accepted that nutrition is essential for the growth and development of the child and entire family.

Apart from teachers and medical personnel, in most of the groups, participants did not know the use of maternal tetanus immunization on the child during pregnancy and after birth. They said it's an injection given to people injured by metal objects or rod metals but they have never understood why pregnant women and children are receiving vaccinations. Some of the participants in different groups revealed that, they preferred enema for their wives when they are pregnant as compared to other preventive measures. They went ahead to mentioned the different types of enema preventive measures (two weeks, one month, three months, six months...) and that a pregnant woman that is faithful at the enema prescription, 
she and the child will always be in good health and she will give birth to children with less labour pains and labour duration. Even after delivery, she is required to take enema to clean her system and purify the breast milk for the growth and development of the baby and health of the mother.

In the Muslim group, while a major participant appreciated tetanus vaccination, added that we should not forget local herbs that can be used to prevent major illnesses. He said this quoting their fore-fathers who were not opportune to visit hospitals or take medical drugs, yet they grew stronger and get to old age using just the natural herbs. This means that the local herbs could be use to prevent diseases even today. Other health inputs mentioned by groups include: education and counseling and direct clinical care.

Views about the Benefits from Better Health. We initially observed that participants of the different groups had not yet considered the benefits of parents and child health with respect to: future family income; extra time for additional work; labour market participation opportunities; self employment opportunities; quality of schooling; child future job and income earning opportunities. This means that they have actually been enjoying such benefits but did not know they were as a result of better family and child health; however, after a lot of clarification from the facilitator, the group members started sharing their opinions, perceptions and views.

A Systemic group member revealed that in the year 2012, his wife who registered for the entrance examination in to Higher Teachers Training College did not write the exam because his third son was very ill, implying that if the son where to be in good health, he could have preferred the baby sitter (domestic assistant) to stay with the child while his wife sit the entrance examination. Another member noted 'my sister in law actually began her financial daily collection-business (self employment) after the health of her children became stable and today she has become financially independent. In another group (Other Protestant), a member said the money she often reserved in her house for precautionary motive, is saved in the bank in an account she called 'bonus account'. She added that with the 'bonus account' in 2011, she started a charcoal business and today, the money has transformed the family status, because she bought five motor taxis and employed five youths that are presently working for her.

A trader participant in the protestant non-mainline group shared the experience she had with her children. She began by mentioning that she has six children alive, so she explained that, the children that did not disturbed her with illnesses, actually spoke by one year six months, they equally went to school earlier and are relatively doing well even as grown-ups more than their brethren who were ill at childhood. So according to her, illness for children is a major obstacle for both the children and their parents. Other groups had similar stories but without classical examples. To some participants, it was a forum to learn new things while to others it was a forum to share experience but in general the groups concluded that there are still many untold benefits when the children and family at large are in good health.

Views about Better Child Health and Complementary Activities. Our concern in this section is to identify the complementary or additional activities that could increase production and income if the children are enjoying good health and to know how the parent are using the extra time accrue to them by virtue of good health, to improve their family income or family status. In an attempt to verify these issues, a participant of the protestant non-mainline group, said whenever her children and family members are in good health, she will used the extra time to buy much 'unpilled melon' (locally known in Cameroon as egusi) that cost 250 FCFA per cup to do the pilling herself at home. However, when the children are ill, she will prefer to buy already pilled melon that cost 450FCFA per cup from the market. So she concluded that whenever her children are sick, she is always 'very poor' and when her children are healthy, she is always 'very rich'.

A widow of Systemic group, unveiled that since 2005, every year she planted at least 200 suckers of plantains, however, in 2010 she succeeded to plant only 47 suckers because her last baby girl, that was put in an incubator in the hospital after delivery (premature with birth weight $<2500 \mathrm{~g}$ ) was always sick. The child's illness prevented her from going to "bush 
villages" to buy suckers as well as also reduced her required capital for her business. In another occasion, a participant resident in Mamfe municipality affirmed that she and her husband are presently undertaking a master degree programme in Agribusiness - University of Dschang because of the stability in their first daughter's health. Initially she noted "we registered in the first year in the programme but could not make it because the baby was tender and always very ill, however, now she is in nursery two, strong and sound we can now move and stay for two weeks in Dschang without being afraid of any health embarrassment".

A food hawker, told her group members that every Saturday she increases the quantity of food she prepares for sale and at times makes even twice the profit she may make during the rest of the other days, because on every Saturday her older children stay at home to take care of their younger brother who has a leg disability while she concentrates in the market. Where as, from Monday to Friday of the week she goes to the market only after 02PM when the older children are back from school.

Views about the Benefits of Maternity Leave and Better Child Health. In the different groups the participants said it's a period to rest and take care of the child as well as concentrate in domestic activities that they used to pay others to do for them. On another occasion, a group member said, during her leave, she went to school simply because she had registered in school before; it was not the health of the child that prompted her to do so. Not with standing a parent said it was during the maternity leave of the wife that she upgraded her computer knowledge. While another noted that, it was during the wife's maternity leave that she decided to attend evening classes to write the Advanced Level Examination. In actual terms, the participants instead laid emphasis in doing many things: schooling, trading, visiting during their annual leave and not maternity leave.

Views about Decision making concerning Family Health. Being the Christians, Muslim or Systemic group, the ideas of the participants were convergent as they said it's the family head (i.e. either father or mother) that decides on the family health. The Muslim and systemic groups emphasis that only the father has to decide while others noted that it can either be the father or mother and to an extent the most educated person in the household.

Views about Health Interventions. Most groups underscored that the government should subsidize the prices of children wears such as dippers, napkins and drugs as well as health treatment. The sales of children drugs are expensive in pharmacies, hence for parent to increase their investment power, let the government subsidize these prices, for it's a means to reduce poverty and inequality. Group members also asserted that the government should also increase family allowance especially during maternity leave to help the parent exploit the extra time from better child health to do business and other money making activities. Non-governmental organizations (NGOs) can make available credit facilities to parent to ease the upbringing of children.

Main result from focus group discussions in relation to child health determinants. As concerns the focus group, each group was fairly uniform in terms of age, sex, region of origin and stage in their life course and the education system. Despite some minor deviations, their responses suggest that their concerns were very much grounded in their immediate experiences and everyday concerns.

From the findings of the various domains above, we observed that a few general issues were identified as relevant to all domains. Firstly as concerning access to public goods, we observed that generally nearness to market and schools for children is not a major issue. On the contrary there is a general absence of adult literacy program, poor roads with no actual public transport vehicles as well as long distances to the hospital and high prices for drugs. Secondly, as to what concerns input to health, sanitation and nutrition is the most applicable, vaccination is good but should be used alongside traditional enema that can either be oral or 'support-citrate' (through anus).

Considering better child health and its effects on parents' income, time and complementary labour market participation opportunities; self employment opportunities; quality of schooling; child future job and income earning opportunities; we observed that there are many untold benefits the parents enjoy as a result of better child health. With respect to time benefit, the groups noted that in addition to other things, they use the extra 
time offered to them by virtue of better child health to do the work they used to pay people to do and by so doing they saved much money than otherwise. In a nutshell, we observed that whenever the children are in good health, most civil servant parents will want to invest their time in doing those activities they used to pay others to do for them as well as take extra classes to update their career, most farmers have sacrifice such periods to work more in their farms to increase their productivity, businessmen will increase the stock of goods and make many more trips than otherwise. Inter-urban and taxi drivers said, it's a good opportunity to make much money in transporting people while others share similar views. As regards improved family income, most women talked of indulging in to different business lines while farmers talk of increasing the amount of time sacrifice in planting and taking care of their farms and consequently production.

The groups generally accepted that maternity leave is a period of rest and to take care of the child and domestic activities. They in turn recommended annual work leave, where they can engage in doing multiple economic activities. Most groups also accepted that it's the father that takes decision for family health but in the absence of the father, the mother or eldest person in the house can do. While with respect to policy in health intervention, the groups noted that child medication and cloths should be subsidies by the government.

Documenting the determinants of child health as informed by FGD , we observed that comparing what the people say as we have discuss in the different views, we realize that the use of vaccination is a major input into child health. They also mention sanitation, counseling and education, direct clinical care, traditional enema and divine prayers to God as complementary health input to confirm the complementary hypothesis of increased birth weight. In addition we observed that during the group discussion, factors such as education, sex, occupation, household head, place of origin/resident, religion and age differences of the participants play a major role in the understanding of child health. Comparing therefore what the people say with the results of DHS as revealed in (Mwabu, 2009), we notice that the two findings are similar; hence, confirming the situation of child health, so far as documenting the determinants of child health in Cameroon is concern.

Main result linking $\mathrm{CH}$ to MLFP and HAE from what the people say. Following the discussion of the different domains in the groups, we realized that if households (parents and children) are in good health, parents are expected to benefit from savings on medical expenditure and extra time that could be deployed to other income earning activities if opportunities exist. In listening to life testimonies from group participants, we notice that much money is actually being saved because the extra time from better health increases the chances of the mother (even the father) to participate in the labour market (including self employment) or to do such domestic jobs they used to pay for and so increases the family income.

The increased family income is use to send children to better schools, carter for their wellbeing as well as to promote asset growth and redistribution, thus, improving economic well-being and reducing poverty. In case of retirement or sudden retrenchment from the labour market, one can make use of the accumulated assets (tangible and intangible) to increase the family income and maintain well-being, hence, reducing the psychological trauma on parents due to poverty. These results clearly verify the link between child health, MLFP and HAE in Cameroon.

Since FGD is a qualitative method of analyzing health issues, aimed at obtaining indepth information on concepts, perceptions and ideas (Crokett et al., 1990) therefore, in bridging research gap and policy information, FGD can be useful in providing an insight into different opinions among various participants involved in the discussion.

\section{CONCLUSION}

This paper is entitled "Linking CH, MLFP and HAE in Cameroon: what the people say". The objectives include: (1) to document the determinants of child health as informed by focus groups discussion. (2) To analyze what the people say concerning the association between 
child health and MLFP. (3) To explore the perception people on the effects of child health on asset accumulation and (4) to suggest public policies on the basis of the findings.

We use seven FGDs to explore what the people say based on different health domains: (1) access to public goods; (2) inputs to health; (3) benefits from better health; (4) better child health and complementary activities; (5) benefits of maternity leave and better child health, (6) decision making concerning family health (7) health Interventions. The focus group is made of 07 groups and eight participants made of housewife, traders, farmers, drivers, teachers, technicians, medical personnel and military. The groups are catholic, protestant mainline, protestant non-mainline, other protestant, muslin and systemic group and traditional belief.

We find out that, parent make use of the extra time accrue to them due to better health for their children and family to do extra work that fetch them money. The increased family income is use to send their children to better schools, carter for their wellbeing as well as to promote asset growth and redistribution, thus, improving economic well-being and reducing poverty. In case of retirement or sudden retrenchment from the labour market, one can make use of the accumulated assets to increase the family income and maintain well-being, hence, reducing the psychological trauma on parents due to poverty.

Based on what the people say, the concept of child health with respect to MLFP and HAE can be viewed through five different conceptual lenses: need, rights (medical care, freedom and opportunities), poverty, quality of life and social exclusion. We therefore, recommend that decision makers and actors concern with child health issues should consider, ease and promote these child outcomes for this is the key to narrow the poverty and inequality gap between the poor and non-poor, rural and urban household residence, married and unmarried, employed and the unemployed, promote maternal labour force participation and household wealth accumulation.

\section{REFERENCES}

1. Almond D, Chay K and David L (2005): The Costs of Low Birth Weight, Quarterly Journal of Economics, August, 1031-1083.

2. Baye M (2010): Contemporaneous Household Economic Well-being Response to Preschool Children Health Status in Cameroon. Botswana Journal of Economics

3. Beresford B, Rabiee P and Sloper P (2007): Priorities and Perceptions of Disabled Children and Young People and Their Parents Regarding Outcomes from Support Services, Social Policy Research Unit, University of York, York.

4. Basch C, DeCicco I and Malfetti J (1989): A focus group study on decision processes of young drivers: reasons that may support a decision to drink and drive Health Education Q, 16 389-96.

5. Basch C (1987): Focus group interview; an underutilized research technique for improving theory and practice in health education, Health Education Q. 14 411-48

6. Barker G and Rich S (1992): Influence on adolescent sexuality in Nigeria and Kenya: findings from recent focus-group discussions, Studies in Family Planning, 23, 199-210.

7. Bender $D$ and Ewbank D (1994): The focus group as a tool for health research: issues in design and analysis. Health Transition Review, Vol. 4, No. 11994

8. Bogardus E (1926): The group interview, J Applied Sociology, 10, 372-82

9. Chavez L, Matias-Carrelo L, Barrio C. and Canino G (2007): The Cultural Adaptation of the Youth Quality of Life Instrument-Research Version for Latino Children and Adolescents, Journal of Children and Family Studies, 16, 75-89.

10. Case A and Deaton A (2005):"Health and wealth among the poor: India and South Africa compared. American Economic Review, papers and proceedings; vol. 95(2)

11. Crockett S, Heller K, Merkel J and Peterson J (1990): Assessing beliefs of older rural Americans about nutrition education: Use of the focus group approach, J American Dietetic Association, 90, 563-7.

12. Counterpoint Research (2008): Childhood Wellbeing: Qualitative Research Study. Research Report DCSF-RW031, Department for Children, Schools and Families, London 
13. Detmar S, Bruil J, Ravens-Sieberer U, Gosch A, Bisegger C and the European KIDSCREEN group (2006): The use of focus groups in the development of the KIDSCREEN HRQL questionnaire, Quality of Life Research, 15, 1345-1353.

14. Dahlgen $P$ (1988): What's the meaning of this/ Views' plural sense-making of TV news, Media, Culture and Society, 10,285 - 301.

15. De Nardi M, French E, and Jones B (2010): Why Do The Elderly Save? The Role of Medical Expenses, Journal of Political Economy, 118(1), 39-75.

16. Ellermann C (2007): Influences on the Mental Health of Children Placed in Foster Care, Journal of Family and Community Health, 30, 2S S23-S32.

17. Fattore T, Mason J and Watson E (2009): When Children are Asked About Their Wellbeing: Towards a Framework for Guiding Policy, Child Indicators Research, 2, 57-77.

18. Grossman M (1972): On the concept of health capital and the demand for health. Journal of Political Economy, Vol. 80: 223-255.

19. Glazer B and Strauss A (1967): The Discovery of Grounded Theory Chicago: Aldine

20. Glewwe P (2008): Why does mother's schooling raise child health in developing countries? Evidence from Morocco, .Journal of Human Resources 34(1), 124-159

21. Grewal I, Lewis J, Flynn T, Brown J, Bond J and Coast J (2006): Developing Attributes for a Generic Quality of Life Measure for Older People: Preferences or Capabilities?, Social Science and Medicine, 62, 8, 1891.

22. Grunig L (1990): Using focus group research in public relations, Public Relations Review, $1,36-49$

23. Hubbard G, Skinner J and Stephen P (1995): "Precautionary Saving and Social Insurance." Journal of Political Economy, 103(2): 360-99.

24. Hoijer B (1990): Studying views' reception of television programmes: theoretical and methodological considerations, European J Communication, 5, 29-56

25. Kitzinger J (1994): The methodology of focus Groups: the importance of interaction between research participants: Journal of Sociology of health and illness. Vol, 16 No 1 1994

26. Khan $M$ and Manderson L (1992): Focus groups in tropical diseases research, Health Policy and Planning, 7, 56-66

27. Kumar R and Mitra A (2009): Growth, Health and Poverty: A Cross-Country Analysis. Journal of International Economic Studies, No. 23, pp. 73-85

28. Lelièvre E and Gauthier A (1994): "L'emploi des femmes en Europe : inégalités, discontinuité, politiques sociales, in MIRE (Mission recherche du ministère des Affaires sociales, de la Santé et de la Ville), Rencontres et Recherches, comparer les systèmes de Protection Sociale en Europe, Rencontres d'Oxford, 1, 493-518

29. Lucas R (1988): On Mechanics of Economic Development. Journal of Monetary Economics, Vol. 22, No.1, 03-42

30. Middleton D and Edwards D (1990): Collective Remembering. London; Sage

31. Morgan D (1988): Focus Groups as Qualitative Research. Newbury Park: Sage Publications.

32. Morgan D (1997): Focus Groups as Qualitative Research, Sage

33. Merton R (1956): The Focused Interview: A group of the bureau of applied social research, Columbia University.

34. Mwabu G (1998): Health Development in Africa, Economic Research Papers No. 38. African Development Bank.

35. Porcellato L., Dughill L and Springett J (2002) Using focus groups to explore children's perceptions of smoking: reflections on practice, Health Education, 102, 6, 310-320

36. Ronen G, Rosenbaum P, Law M. and Streiner D (2001): Health-related quality of life in childhood disorders: A modified focus group technique involving children, Quality of Life Research, 10, 1, 71-79.

37. Soares and Rodrigo R (2007): Health and the evolution of welfare across Brazilian municipalities. Journal of Development Economics, Vol. 84, No. 2 
38. Tambi D and Nkwelle J (2013): Child health and Maternal labour Supply: A chi square approach. International Journal of Finance, Economics and Management, Vol. 2, No 2, 2013

39. Tsafack N and Zamo-Akono C (2009): Fertility, Health and Female Labour Force Participation in Urban Cameroon 2009. International Business Research Journal, www.ccsenet.org/ibr.

40. Thomas D and Elizabeth F (2002): Health, Nutrition and Prosperity: a Microeconomic perspective. Bulletin of the World Health Organization, Vol. 80, No. 2

41. Waghom and Lloyd C (2005): 'The employment of people with mental illness', Australian e-Journal for the Advancement of Mental Health, vol. 4, issue 2.

42. Wee H, Chua H and Li S (2006): Meaning of health-related quality of life among children and adolescents in an Asian country: A focus group approach, Quality of Life Research, $15,5,821-831$.

43. Young B, Rice H, Sixon-Woods M, Colver A and Parkinson K (2007): A qualitative study of the health-related quality of life of disabled children, Developmental Medicine \& Child Neurology, 49, 660-665.

44. Zimmerman M (1990): Assessing the acceptability of Norplant implants in four countries: findings from focus group research, Studies in Family Planning, 21, 92-103. 